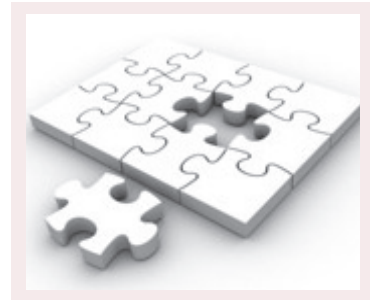

In an effort to facilitate the selection of appropriate peer reviewers for Curationis, we ask that you take a moment to update your electronic portfolio on www.curationis.org.za for our files, allowing us better access to your areas of interest and expertise, in order to match reviewers with submitted manuscripts.

If you would like to become a reviewer, please visit the journal website and register as a reviewer.

To access your details on the website, you will need to follow these steps:

1. Log into the online journal at http://www. curationis.org.za

2. In your 'user home' [http://www.curationis. org.za/index.php/ curationis/user] select 'edit my profile' under the heading 'my account' and insert all relevant details, bio statement and reviewing interest.

3. It is good practice as a reviewer to update your personal details regularly to ensure contact with you throughout your professional term as reviewer to Curationis.

Please do not hesitate to contact me if you require assistance in performing this task.

Anele Ntswayi submissions@curationis. org.za

Tel: +27 (0)21975 2602

Fax: +27 (0)21 9754635

\title{
CURATIONIS
}

Journal of the democtatic Nursing Organisation of South Africa

Curationis recognises the value and importance of the peer reviewer in the overall publication process - not only in shaping the individual manuscript, but also in shaping the credibility and reputation of our journal. We are committed to the timely publication of all original, innovative contributions submitted for publication. As such, the identification and selection of reviewers who have expertise and interest in the topics appropriate to each manuscript are essential elements in ensuring a timely, productive peer review process.

We would like to take this opportunity to thank all reviewers who participated in shaping this volume of Curationis:

\section{Annah Rakhudu}

Busisiwe Nyantumbu

Botiumelo Setlalentoa

Braam Hoffmann

Busisiwe Bhengu

Christine February

Dorah U. Ramathuba

Erhabor S. Idemudia

Elma W. Kortenbout

Esmeralda Ricks

Ethelwynn Stellenberg

Eva Manyedi

Freda Daniels

Gloria Tshweneagae

Hester C. Klopper

Hester Julie

Jacobs Ngako

Janetta Roos

Johanna Mathibe-Neke

John Williams

Karien Jooste

Kathleen Nokes

Lize Maree

Malmsey Sengane

Margaret Masilo

Maria Maputle

Martha Pinkoane
Mary Chabel

Masamo Lekhuleni

Mmapheko Peu

Momafrench Mbombo

Ntombifikile G. Mtshali

Nelouise Geyer

Nokuthula Sibiya

Nomaphelo Magadla

Ntombizodwa Linda

Padmini Pillay

Penelope Orton

Petra Brysiewicz

Prosper Lutala

Rene Phetlhu

Rachel Lebese

Sinegugu Duma

Sarie Human

Susan C.D. Wright

Salomé Meyer

Sipho Mkhize

Tebogo M. Mothiba

Thandisizwe Mavundla

Thembelihle Ngxongo

Valerie Ehlers

Weziwe Sikaka

Yolanda Kolisa

We appreciate the time taken to perform your review successfully. 